Pesq. Vet. Bras. 35(9):817-821, setembro 2015 DOI: 10.1590/S0100-736X2015000900008

\title{
A bull breeding soundness evaluation system with greater emphasis on scrotal circumference ${ }^{1}$
}

\author{
Jose A. Garcia-Paloma²
}

\begin{abstract}
Garcia-Paloma J.A. 2015. A bull breeding soundness evaluation system with greater emphasis on scrotal circumference. Pesquisa Veterinária Brasileira 35(9):817-821. Centro de Biotecnología Animal, Servicio Regional de Investigación y Desarrollo Agroalimentario, Camino de Rioseco 1225, Deva, Gijón 33394, Asturias, Spain. E-mail: jagarcia@serida.org

Bull breeding soundness evaluation (BBSE) is a method applied to reduce the risk of using subfertile bulls in herds. There are currently two BBSE systems, those of the Society for Theriogenology (SFT) and the Western Canadian Association of Bovine Practitioners (WCABP). Scrotal circumference (SC), sperm motility (SM) and normal sperm (NS) of 454 bulls aged between 12 and 15 months of a Spanish beef breed were used to compare both systems, and since there is no agreement on that BBSE system must be applied in Spain, a single one was proposed for its consideration. SC was adjusted to 15 months (SC15) and the mean of the BBSE traits was: SC15 $(34.2 \pm 2.4 \mathrm{~cm})$, SM $(76.6 \pm 14.6 \%)$ and NS $(76.8 \pm 12.3 \%)$. In the PROPOSED system, the SM and NS thresholds were those defined by the WCABP system, while the SC15 thresholds were set by combining the SFT threshold and SC15 \pm 1 SD in order to establish four classification categories, the three proposed by the WCABP system: unsatisfactory, questionable and satisfactory, and other category, called superior, for bulls with $\mathrm{SM} \geq 60 \%, \mathrm{NS} \geq 70 \%$ and SC15 $\geq$ Mean +1 SD. The PROPOSED system scored fewer bulls as unsatisfactory than the SFT and the WCABP systems $(8.6 \%, 23.6 \%$ and $22.5 \%$, respectively; $\mathrm{P}<0.01$ ), while the percentage of bulls from worst to best in the other three categories under the PROPOSED system was: $26.0 \%, 54.2 \%$ and $11.2 \%$, respectively. In conclusion, the PROPOSED system gives more emphasis to SC, sets differences between bulls classified as satisfactory by the other systems and can be considered a good system for Spain and for other countries that have no defined their own system.
\end{abstract}

INDEX TERMS: Bull, breeding soundness, scrotal circumference, sperm motility, sperm morphology.

\section{INTRODUCTION}

Bull breeding soundness evaluation (BBSE) is a method applied under field conditions aimed at reducing the risk of using subfertile bulls in herds. This method is essentially based on the physical analysis of bulls and their semen, but can be complemented by the assessment of serving capacity, carrier status of transmissible diseases and genetic faults. Only on the main traits of the BBSE system will be discussed in this paper: scrotal circumference (SC), normal sperm (NS) and progressive sperm motility (SM).

\footnotetext{
${ }^{1}$ Received on January 12, 2015.

Accepted for publication on September 1, 2015.

${ }^{2}$ Centro de Biotecnología Animal, Servicio Regional de Investigación y Desarrollo Agroalimentario (SERIDA), Camino de Rioseco 1225, Deva, Gijón 33394, Asturias, Spain. E-mail: jagarcia@serida.org
}

The Society for Theriogenology (SFT) published the first guidelines for interpreting the BBSE system in 1983 (Ball et al. 1983) and, years later, a revised system that is the one currently applied in the United States (Hopkins \& Spitzer 1997). Due to some differences regarding criteria for setting the SC, NS and SM thresholds, the Western Canadian Association of Bovine Practitioners (WCABP) subsequently proposed another alternative BBSE system (Barth 2000). Therefore, given the existence of two models of the BBSE system, the standardization of the method in at least each country has been repeatedly cited as a necessity (Fordyce et al. 2006, Palmer et al. 2013). Whether with respect to one model of the BBSE system or a combination of both, in addition to the SFT and the WCABP associations, the following stand out for having promoted and reached consensus on the BBSE method to employ: 
the Australian Cattle Vets (ACV), the South African Veterinary Association (SAVA) and the British Cattle Veterinary Association (BCVA) (Fordyce et al. 2006, Irons et al. 2007, Penny 2009).

SC is an easy to measure trait, highly repeatable between technicians and positively correlated with semen production and quality (Coe 1999, Siddiqui et al. 2008). Bulls of beef breeds selected for milk production, such as Simmental and Brown Swiss, develop larger testicles than bulls of non-selected breeds like Charolais and Hereford. Bulls belonging to breeds which achieve a larger mature size, usually have larger testicles than bulls of smaller breeds, while bulls belonging to Bos taurus breeds also have larger testicles than those belonging to Bos indicus breeds (Barth 2000, Menegassi et al. 2011). Besides reaching puberty at a younger age (Smith et al. 1989), bulls with a high SC transmit earlier puberty to offspring and a greater productive life to their daughters (Moser et al. 1996, Siddiqui et al. 2008). Puberty in bulls is defined as the age at which the first ejaculate contains a minimum of $50 \times 10^{6} \mathrm{sperm} / \mathrm{mL}$, with at least $10 \%$ of SM (Lunstra \& Echternkamp 1982). Variation in age at puberty was observed among and within breeds, ranging from 8 to 12 mo, although the SC at puberty was not different between them $(27.9 \pm 0.2 \mathrm{~cm}$ ) (Lunstra et al. 1978, Lunstra \& Echternkamp 1982). The percentage of normal sperm at puberty is low, with proximal cytoplasmic droplet (PCD) being the main defect (Madrid et al. 1988, Brito et al. 2004). Two months later, however, droplets disappear and semen usually reaches maturity ( $\geq 60 \% \mathrm{SM}$ and $\geq 70 \% \mathrm{NS}$ ) (Arteaga et al. 2001, Brito et al. 2012). As heritability of SC is moderate to high (0.41-0.57) (Bourdon \& Brinks 1986, Kealey et al. $2006)$, it has been suggested that rapid improvement in testicular size with its associated effects can be obtained via selection. The SFT system does not consider breed or age when setting the SC threshold, so the SC threshold is the same $(30 \mathrm{~cm})$ for bulls of any Bos taurus breed between 12 and 15 mo of age (Hopkins \& Spitzer 1997). The WCABP system sets the SC threshold for each breed and age as one standard deviation below the mean (Coulter et al. 1987), which means that $16 \%$ of bulls with the smallest SC can be culled. Both systems classifie bulls with satisfactory or unsatisfactory SC score, but do not differentiate between satisfactory bulls, therefore, the positive effects of SC above described are not considered. In some breeds like Belgian Blue, muscular hypertrophy or the double muscling condition has been associated with a delay in puberty, small testicles and poor seminal quality (Arthur 1995, Bellinge et al. 2005, Hoflack et al. 2006b).

As regards SM and NS, the SFT system considers two categories of bulls also (satisfactory and unsatisfactory), while the WCABP system adds another category called questionable for bulls whose values of SM or NS are slightly below the set threshold.

In Spain, a lack of consensus is observed among veterinarians that apply the BBSE methodology. Hence, the aim of this paper was to analyze the two BBSE systems of reference, the SFT and the WCABP, and to propose a single one to promote discussion towards a common system.

\section{MATERIALS AND METHODS}

Ethics statement. The study was conducted at performance testing station of the Asturiana de los Valles (AV) breed, Llanera, Asturias, Spain, in compliance with the Ethics Principles in Animal Experimentation, being approved by the Ethics Committee on Animal Experimentation of Servicio Regional de Investigación y Desarrollo Agroalimentario, Principado de Asturias, Spain.

Bulls, SC and semen quality evaluation. 454 bulls aged between 12 and 15 mo and reared between 2006 and 2011,were used in this study. AV is a Spanish beef breed with the double muscle condition, a muscular hypertrophy associated with the nt821 mutation of the myostatin gene. The bulls employed in the study were genotyped using the oligonucleotide ligation assay (OLA) methodology (Miranda et al. 2002), all being found to be homozygotes for the nt821 mutation.

Each year, the best cows of the breed in terms of their muscular conformation and weight of their calves at weaning were considered to select male calves for testing. After weaning, the calves reached the testing station at about 6 mo of age and received the same management and diet until 12 or 15 mo of age, when the test was concluded. The diet supplied barley straw ad libitum and an average of $6 \mathrm{~kg} /$ day of concentrate containing 15\% crude protein and $9 \mathrm{MJ} / \mathrm{Kg}$ metabolisable energy on a dry matter basis. The bulls grew an average of $1.4 \mathrm{~kg} /$ day during this period. At the end of the test period (spring, summer or autumn), the BBSE system was performed on bulls that had previously passed an established threshold for muscular conformation, breed standard and daily gain. At BBSE, the bulls weighted $532 \pm 45 \mathrm{~kg}$ and had a body condition score of $4.2 \pm 0.4$ on a scale of $1-5$ (Wildman et al. 1982).

A general physical examination was carried out, paying greater attention to the reproductive organs (penis, scrotum, testicles, prostate, seminal vesicles and ampullae). SC was measured to the nearest $0.5 \mathrm{~cm}$ using a scrotal tape around the widest circumference (Ideal Instruments, Lexington, KY, USA). Semen was obtained by electroejaculation using ElectroJac $5 \AA$ (Ideal Instruments, Lansing, MI, USA) up to three times at weekly intervals if semen quality was not satisfactory $(<60 \%$ of SM or $<70 \%$ of NS); the best sample was chosen for this study. A water jacket was used to maintain the temperature of the collection tube at $3{ }^{\circ} \stackrel{\circ}{ } \mathrm{C}$. After collection, sperm concentration was obtained using an Accucell ${ }^{\circledR}$ spectrophotometer (IMV Technologies, L'Aigle, France), and semen was diluted to $60 \times 10^{6}$ sperm $/ \mathrm{mL}$ using Bioxcell ${ }^{\circledR}$ as extender (IMV Technologies, L'Aigle, France). The evaluation of SM was performed using a phase-contrast microscopy at 200x magnification. The same dilution with $0.9 \% \mathrm{CINa}$ was used to evaluate NS with eosin-nigrosin staining. A random sample of 200 cells was observed by oil immersion using light microscopy at 1000x magnification. Each sperm was classified as normal or abnormal considering the following abnormalities: acrosome, head, separated head, PCD, midpiece and tail (Barth \& Oko 1989). If a sperm had several abnormalities, only the abnormality most related to infertility was taken into consideration (Hoflack et al. 2006a). A single veterinarian trained in spermatology, maintaining strict control of the cleanliness and temperature of $37^{\circ} \mathrm{C}$ in all materials and extenders, performed semen evaluation.

Statistics. Statistical analyses were carried out using SAS, Version 9.2 (SAS Institute, Inc.). Descriptive statistics of SC were obtained and outliers were deleted using the interquartile range method (Schlotzhauer \& Littell 1997). The effect on SC of year, season of the year and age (d) was determined; the SC was adjusted to 15 mo of age (SC15) using the partial regression coefficient of the reduced model and its normal distribution was verified using the Shapiro-Wilk normality test. The influence of age (mo) on SM, 
NS and sperm abnormalities and the effect of the BBSE system on the percentage of bulls classified in each category were also analyzed. Using the general linear model (GLM), least-squares means were generated to make comparisons between effects. The differences between values were considered statistically significant when $\mathrm{P}<0.01$.

\section{RESULTS}

The mean $( \pm \mathrm{SD}) \mathrm{SC}$, age, $\mathrm{SM}$ and NS for the 454 yearling AV bulls was: $33.4 \pm 2.4 \mathrm{~cm}, 13.6 \pm 0.9 \mathrm{mo}, 76.6 \pm 14.6 \%$ and $76.8 \pm 12.3 \%$, respectively.

Age (mo) did not affect SM, although NS was influenced by age. Bulls of 12 mo had less NS than older bulls $(71.4 \%$ and $77.4 \%$, respectively; $\mathrm{P}<0.01$ ), PCD being the only sperm abnormality that justified this difference $(8.3 \%$ and $5.0 \%$, respectively) (Table 1 ).

Age (d) affected SC $(\mathrm{P}<0.0001)$, although year, season of the year and double interactions between effects did not. SC was adjusted to 457.5 days (15 mo) through the partial regression coefficient of SC on age $(0.0191 \mathrm{~cm} /$ day $)$ using the following formula: SC15=SC+0.0191*(457.5-age (d)). SC15 had a normal distribution (Shapiro-Wilk test, $\mathrm{P}=0.1555$ ) with mean $34.2 \pm 2.4 \mathrm{~cm}$; therefore, the Empirical Rule of normal distribution could be used to set the thresholds and classification categories of bulls respect to SC15. SC15 was used in the PROPOSED system in contrast with the SFT system which valued the SC without adjusting for breed or age in bulls between 12 to 15 mo and in contrast with the WCABP system which valued the SC adjusting for breed and for age in months instead in days. The following criteria were considered to set the SC15 categories: the SFT threshold $(30 \mathrm{~cm})$, the SC15 mean minus one SD $(31.8 \mathrm{~cm})$ and the SC15 mean plus one SD $(36.6 \mathrm{~cm})$ (Table 2). The percentage of bulls classified for each of the

Table 1. Mean \pm SD for sperm motility, normal sperm and proximal cytoplasmic droplet (PCD) of yearling Asturiana de los Valles bulls for age

\begin{tabular}{ccccc}
\hline Age (mo) & No. bulls & $\begin{array}{c}\text { Sperm motility } \\
(\%)\end{array}$ & $\begin{array}{c}\text { Normal sperm } \\
(\%)\end{array}$ & $\begin{array}{c}\text { PCD } \\
(\%)\end{array}$ \\
\hline 12 & 45 & $77.4 \pm 2.2$ & $71.4 \pm 1.8 \mathrm{a}$ & $8.3 \pm 1.0 \mathrm{a}$ \\
13 & 175 & $75.8 \pm 1.1$ & $76.0 \pm 0.9 \mathrm{a}, \mathrm{c}$ & $5.9 \pm 0.5 \mathrm{a}, \mathrm{c}$ \\
14 & 158 & $76.6 \pm 1.2$ & $77.6 \pm 1.0 \mathrm{~b}, \mathrm{c}$ & $4.8 \pm 0.5 \mathrm{~b}, \mathrm{c}$ \\
15 & 76 & $78.3 \pm 1.7$ & $80.4 \pm 1.4 \mathrm{~b}$ & $3.3 \pm 0.8 \mathrm{~b}$ \\
\hline
\end{tabular}

a,b,c Values with different superscript letters in the same column differ significantly at $\mathrm{P}<0.01$.
Table 2. Differences between the SFT, WCABP and PROPOSED systems with respect to the thresholds and categories of classifying bulls

\begin{tabular}{|c|c|c|c|}
\hline \multirow[t]{2}{*}{ Trait and category } & \multicolumn{3}{|c|}{ System and thresholds } \\
\hline & SFT & WCABP & PROPOSED \\
\hline \multicolumn{4}{|c|}{ Scrotal circumference $(\mathrm{cm})$} \\
\hline Unsatisfactory & $<30$ & $<$ Threshold & $<30$ \\
\hline Questionable & & & $30-31.8$ \\
\hline Satisfactory & $\geq 30$ & $\geq$ Threshold & $31.9-36.5$ \\
\hline Superior & & & $\geq 36.6$ \\
\hline \multicolumn{4}{|l|}{ Normal sperm (\%) } \\
\hline Unsatisfactory & $<70$ & $<50$ & $<50$ \\
\hline Questionable & & $50-69$ & $50-69$ \\
\hline Satisfactory & $\geq 70$ & $\geq 70$ & $\geq 70$ \\
\hline \multicolumn{4}{|l|}{ Sperm motility (\%) } \\
\hline Unsatisfactory & $<30$ & $<40$ & $<40$ \\
\hline Questionable & & $40-59$ & $40-59$ \\
\hline Satisfactory & $\geq 30$ & $\geq 60$ & $\geq 60$ \\
\hline
\end{tabular}

Systems: SFT $=$ Society for Theriogenology. WCABP $=$ Western Canadian Association of Bovine Practitioners. PROPOSED = Proposed system to promote consensus in Spain.

four categories of SC15, unsatisfactory, questionable, satisfactory and superior was 2.9\%, 12.3\%, 68.3\% and $16.5 \%$ respectively (Table 3).

Respect to the percentage of bulls classified as unsatisfactory for each of the BBSE tratis, there were significant differences $(\mathrm{P}<0.01)$ between SFT and WCABP systems, SC (4.9\% vs. $18.3 \%)$, SM (1.1\% vs 3.3\%) and NS (19.6 vs. $4.0 \%)$. The final category of BBSE, called breeding soundness (BS) in this paper, was defined for the PROPOSED system similarly to the SFT and WCABP systems, this is, with the same category as the worst evaluated trait (SC, NS or SM). The PROPOSED system had a lower percentage of bulls with unsatisfactory BS score than SFT and WCABP systems (8.6\%, 23.6\% and $22.5 \%$, respectively; $\mathrm{P}<0.01$ ), but it had greater percentage of bulls classified as questionable than the WCABP system (26.0\% vs. $14.1 \%)$. In order to differentiate among bulls classified with satisfactory BS, the superior category was created in the PROPOSED system, considering bulls with a satisfactory semen quality ( $\geq 60 \%$ SM and $\geq 70 \%$ NS) and superior SC15 ( $\geq$ mean plus one SD). The percentage of bulls classified as satisfactory and superior BS under the PROPOSED system (54.2\% and $11.2 \%$, respectively), was similar to the percentage of bulls classified as satisfactory under the WCABP system $(63.4 \%)$ (Table 3).

Table 3. Percentage of yearling Asturiana de los Valles bulls $(n=454)$ classified by category and system with respect to SC, SM, NS and BS

\begin{tabular}{|c|c|c|c|c|c|c|c|c|c|c|c|c|}
\hline \multirow{3}{*}{ Category } & \multicolumn{12}{|c|}{ System } \\
\hline & \multicolumn{4}{|c|}{ SFT } & \multicolumn{4}{|c|}{ WCABP } & \multicolumn{4}{|c|}{ PROPOSED } \\
\hline & $\mathrm{SC}$ & SM & NS & BS & SC & SM & NS & BS & SC15 & SM & NS & BS \\
\hline Unsatisfactory & $4.9^{\mathrm{a}}$ & $1.1^{\mathrm{a}}$ & $19.6^{\mathrm{a}}$ & $23.6^{\mathrm{a}}$ & $18.3^{\mathrm{b}}$ & $3.3^{\mathrm{b}}$ & $4.0^{\mathrm{b}}$ & $22.5^{\mathrm{a}}$ & $2.9^{\mathrm{a}}$ & $3.3^{\mathrm{b}}$ & $4.0^{\mathrm{b}}$ & $8.6^{\mathrm{b}}$ \\
\hline Questionable & & & & & & 4.6 & 15.6 & $14.1^{\mathrm{a}}$ & 12.3 & 4.6 & 15.6 & $26.0^{\mathrm{b}}$ \\
\hline Satisfactory & $95.1^{\mathrm{a}}$ & $98.9^{\mathrm{a}}$ & 80.4 & $76.4^{\mathrm{a}}$ & $81.7^{b}$ & $92.1^{b}$ & 80.4 & $63.4^{\mathrm{b}}$ & $68.3^{c}$ & $92.1^{\mathrm{b}}$ & 80.4 & $54.2^{\mathrm{c}}$ \\
\hline Superior & & & & & & & & & 16.5 & & & 11.2 \\
\hline
\end{tabular}

SFT $=$ Society for Theriogenology. WCABP $=$ Western Canadian Association of Bovine Practitioners. PROPOSED = Proposed system to promote consensus in Spain. SC $=$ Scrotal circumference. SC15 = SC adjusted to $15 \mathrm{mo}$. SM = Sperm motility. NS = Normal sperm. BS = Breeding soundness .

$a, b, c$ Values with different superscript letters in the same row and trait differ significantly at $\mathrm{P}<0.01$. 


\section{DISCUSSION}

The testicular growth of AV bulls, $0.58 \mathrm{~cm} / \mathrm{mo}$, was lower than that reported by Barth (2000) for bulls of Bos taurus breeds between 12 and 14 mo of age and that reported by Bourdon \& Brinks (1986) for Hereford bulls (1 and 0.79 $\mathrm{cm} / \mathrm{mo}$, respectively), though higher than the value reported by Lunstra et al. (1988) for Charolais bulls within the same age range $(0.40 \mathrm{~cm} / \mathrm{mo})$. These references confirm the effect of breed on $\mathrm{SC}$ and the need to have characterized each breed before evaluation of bulls for this trait.

Table 3 shows the effect of the BBSE system on the percentage of AV bulls scored in each SC category. The system with more unsatisfactory bulls was the WCABP system (18.3\%), an expected percentage by the normal distribution of this trait. When the SFT system was used, only $4.9 \%$ of the bulls were classified as unsatisfactory. Unless SC is a selection objective, the criterion proposed by the WCABP system is not advisable because the culling rate may be too high if other selection factors like standard racial, muscular conformation, genetic value, growth rate or physical or semen evaluation are also applied. The questionable category recommended by the PROPOSED system for SC15 $(12.3 \%)$, resolves the disagreement between the SFT and the WCABP systems. The SFT and WCABP systems score bulls as unsatisfactory or satisfactory respect to SC, but do not differentiate among bulls that pass the SC threshold. Therefore, to take into consideration the positive effect of $\mathrm{SC}$ on the reproductive performance of bulls and on the fertility of the female offspring, the superior category of SC15 was established in the PROPOSED system and accounted for $16.5 \%$ of the AV bulls. Overall percentage of bulls with satisfactory and superior SC15 (68.3\% and $16.5 \%)$, was similar to percentage of bulls with satisfactory SC under the WCABP system $(81.7 \%)$.

Regarding SM, important differences between the SFT and the WCABP systems were observed with respect to the threshold for classifying bulls as satisfactory ( $>30$ vs. $>60 \%$, respectively). The percentage of AV bulls classified as satisfactory with these systems was $98.9 \%$ and $92.1 \%$, respectively; $(\mathrm{P}<0.01)$. Employing the SFT system, Kennedy et al. (2002) and Hoflack et al. (2006b) obtained a similar percentage of bulls classified as satisfactory (98\%). Arteaga et al. (2001) using the WCABP system, obtained $94.6 \%$ of satisfactory bulls. SM was not a good trait to detect differences in breeding soundness between bulls, in spite of this, the criterion that the WCABP system uses to set the SM threshold was considered in the PROPOSED system.

AV bulls of 12 mo of age had $8.3 \%$ of PCD, very similar percentage to obtained in western Canada by Arteaga et al. (2001) with yearling beef bulls. Considering the criterion of Entwistle \& Fordyce (2003), only $13.3 \%$ of these $\mathrm{AV}$ bulls had an immature spermiogram (PCD $>20 \%)$. A new evaluation two months later is recommended in these cases, and when the percentage of PCD persists, bulls should be classified as unsatisfactory due to their low fertility (Amann et al. 2000). The NS threshold to classify bulls as unsatisfactory was much more severe in the SFT than in the WCABP system ( $<70 \%$ vs. $<50 \%$, respectively); so the culling rate of bulls for this trait was $19.6 \%$ and $4.0 \%$, respectively; $(\mathrm{P}<0.01)$ (Table 3$)$. The difference between the two percentages (15.6\%) stands for the bulls that the WCABP system classifies as questionable (NS between $50 \%$ and $70 \%$ ). The BBSE system used in Australia also considers this intermediate category and concludes that these bulls are suitable for natural mating, though not for artificial breeding (Fordyce et al. 2006). On the basis of these considerations, we chose the same NS thresholds and categories for the PROPOSED system as those used in the WCABP system.

Although the percentage of bulls with unsatisfactory BS score was similar between the SFT and the WCABP systems (23.6\% vs. $22.5 \%$, respectively), the causes giving rise to this classification were different. NS was the trait that had more influence on BS score under the SFT system, while SC had more influence when the WCABP system was applied. So, a bull classified with satisfactory BS by one system, may be classified as unsatisfactory by the other. Using the PROPOSED system, $8.6 \%$ and $26.0 \%$ of the AV bulls were classified with unsatisfactory and questionable BS score, respectively. The sum of both categories was very similar to that obtained with the WCABP system $(34.6 \%$ vs $36.6 \%$, respectively). So, many of the bulls with unsatisfactory BS under the WCABP system, were classified as questionable under the PROPOSED system due to different guideline to value the $\mathrm{SC}$. The questionable bulls are considered useful for natural mating, but by having moderately reduced their fertility (Barth 2000), could be used in herds with low breeding pressure and should be closely monitored during the breeding season. Barth (2000) and Eppink (2005) consider herds with normal breeding pressure those presenting a bull to female ratio of 1:30-40. 54.2\% of the AV bulls in this study were classified as satisfactory BS and according to Fordyce et al. (2006), as long as the service ability and libido of these bulls are adequate, they should be able to impregnate between $60 \%$ and $90 \%$ of 30 40 healthy, cycling cows within 6 and 9 weeks, respectively. Following the same reasoning, AV bulls classified with a superior BS score $(11.2 \%)$ could be used in herds with higher breeding pressure ( $>40$ cows in herds with compact calving), or when SC is considered as a selection objective. The PROPOSED system can be used in other breeds, but SC15 should be adjusted for each. It is also important to consider that the bulls valued, should have similar conditions of nutritional management and environment to the bulls used for adjustment.

The negative effect of the double muscling on SC and on semen quality reported by Hoflack et al. (2006b) in the Belgian Blue breed, was not observed in AV bulls.

\section{CONCLUSIONS}

Great differences were found between the SFT and WCABP systems with respect to the SC, SM and NS thresholds used to classify the breeding soundness of bulls.

The PROPOSED system, an alternative system with more emphasis on scrotal circumference, establishes differences between bulls classified as satisfactory by the other systems and can be considered a good system for Spain and for other countries that have no defined their own system. 
Acknowledgements.- This research was supported by a project grant from the Plan for Science, Technology and Innovation 2006-2009, belonging to ERDF Operational Programme 2007-2013 from Principado de Asturias (PC10-53) and by the Asturiana de los Valles Cattle Breeders' Association. Our thanks to G. Noval for his assistance in the field work.

\section{REFERENCES}

Amann R.P., Seidel G.E. \& Mortimer R.G. 2000. Fertilizing potential in vitro of semen from young beef bulls containing a high or low percentage of sperm with a proximal droplet. Theriogenology 54:1499-1515.

Arteaga A.A., Baracaldo M. \& Barth A.D. 2001. The proportion of beef bulls in western Canada with mature spermiograms at 11 to 15 months of age. Can. Vet. J. 42:783-787.

Arthur P.F. 1995. Double muscling in catte: a review. Aust. J. Agric. Res. 46:1493-1515.

Ball L., Ott R.S., Mortimer R.G. \& Simons J.C. 1983. Manual for breeding soundness examination of bulls. Theriogenolgy 12:1-65.

Barth A.D. 2000. Bull Breeding Soundness Evaluation. The Western Canadian Association of Bovine Practitioners, Alberta, Canada. 75p.

Barth A.D. \& Oko R.J. 1989. Abnormal morphology of bovine spernatozoa. Iowa State University Press, Ames, IA. 285p.

Bellinge R., Liberles D., Iaschi S., O’Brien P. \& Tay G. 2005. Myostatin and its implications on animal breeding: a review. Anim. Genet. 36:1-6.

Bourdon R.M. \& Brinks J.S. 1986. Scrotal circumference in yearling hereford bulls: adjustment factors, heritabilities and genetic, environmental and phenotypic relationships with growth traits. J. Anim. Sci. 62:958967.

Brito L.F.C., Barth A.D., Wilde R.E. \& Kastelic J.P. 2012. Effect of growth rate from 6 to 16 months of age on sexual development and reproductive function in beef bulls. Theriogenology 77:1398-1405.

Brito L.F.C., Silva A.E.D.F., Unanian M.M., Dode M.A.N., Barbosa R.T. \& Kastelic J.P. 2004. Sexual development in early- and late-maturing Bos indicus and Bos indicus $\times$ Bos taurus crossbred bulls in Brazil. Theriogenology 62:1198-1217.

Coe P.H. 1999. Associations among age, scrotal circumference, and proportion of morphologically normal spermatozoa in young beef bulls during an initial breeding soundness examination. J. Am. Vet. Med. Assoc. 214:1664-1667.

Coulter G.H., Mapletoft R.J., Kozub G.C. \& Cates W.F. 1987. Scrotal circunference of two year old bulls of several beef breeds. Theriogenology 27:485-491.

Entwistle K. \& Fordyce G. 2003. Evaluating and Reporting Bull Fertility. Australian Cattle Vets, Queensland. 98p.

Eppink E. 2005. A survey of bull breeding soundness evaluation in the south east of Scotland. Cattle Practice 13:205-209.

Fordyce G., Entwistle K., Norman S., Perry V., Gardiner B. \& Fordyce P. 2006. Standardising bull breeding soundness evaluations and reporting in Australia. Theriogenology 66:1140-1148.

Hoflack G., Opsomer G. \& Maes D. 2006a. Assessing bull fertility: The breeding soundness evaluation. Vlaams. Diergen. Tijds. 75:216-227.

Hoflack G., Van Sooma A., Maesa D., de Kruifa A., Opsomera G. \& Duchateaub L. 2006b. Breeding soundness and libido examination of Belgian
Blue and Holstein Friesian artificial insemination bulls in Belgium and The Netherlands. Theriogenology 66:207-216.

Hopkins F.M. \& Spitzer J.C. 1997. The new Society for Theriogenology breeding soundness evaluation system. Vet. Clin. N. Am.-Food Anim. Pract. 13:283-293.

Irons P.C., Nothling J.O. \& Bertschinger H.J. 2007. Bull breeding soundness evaluation in Southern Africa. Theriogenology 68:842-847.

Kealey C.G., MacNeil M.D. \& Tess M.W. 2006. Genetic parameter estimates for scrotal circumference and semen characteristics of Line 1 Hereford bulls. J. Anim. Sci. 84:283-290.

Kennedy S.P., Spitzer J.C., Hopkins F.M., Higdon H.L. \& Bridges Jr W.C. 2002. Breeding soundness evaluations of 3,648 yearling beef bulls using the 1993 Society for Theriogenology guidelines. Theriogenology 58:947-961.

Lunstra D.D. \& Echternkamp S.E. 1982. Puberty in beef bulls: acrosome morphology and semen quality in bulls of different breeds. J. Anim. Sci. 55:638-648.

Lunstra D.D., Ford J.J. \& Echternkamp S.E. 1978. Puberty in beef bulls: hormone concentrations, growth, testicular development, sperm production and sexual aggressiveness in bulls of different breeds. J. Anim. Sci. 46:1054-1062.

Lunstra D.D., Gregory K.E. \& Cundiff L.V. 1988. Heritability estimates and adjustment factors for the effects of bull age and age of dam on yearling testicular size in breeds of bulls. Theriogenology 30:127-136.

Madrid N., Ott R.S., Rao D.N., Parret D.F., Vanderwert W. \& Willms C.L. 1988. Scrotal circumference, seminal characteristics, and testicular lesions of yearling Angus bulls. Am. J. Vet. Res. 49:579-585.

Menegassi S.R.O., Barcellos J.O.J., Peripolli V., Pereira P.R.R.X., Borges J.B.S. \& Lampert V.N. 2011. Measurement of scrotal circumference in beef bulls in Rio Grande do Sul. Arq. Bras. Med. Vet. Zootec. 63:87-93.

Miranda M.E., Amigues Y., Boscher M.Y., Menissier F., Cortes O. \& Dunner S. 2002. Simultaneous genotyping to detect myostatin gene polymorphism in beef cattle breeds. J. Anim. Breed. Genet. 119:361-366.

Moser D.W., Bertrand J.K., Benyshek L.L., McCann M.A. \& Kiser T.E. 1996. Effects of selection for scrotal circunference in Limousin bulls on reproductive and growth traits of progeny. J. Anim. Sci. 74:2052-2057.

Palmer C.W., Persson Y. \& Söderquist L. 2013. Classification of the potential breeding ability of range beef bulls on semen quality parameters in samples collected by transrectal massage - A comparison of the Swedish and Canadian systems. Anim. Reprod. Sci. 140:124-130.

Penny C.D. 2009. The development of a UK bull breeding soundness evaluation certificate. Cattle Practice 17:64-70.

Schlotzhauer S.D. \& Littell R.C. 1997. SAS system for elementary statistical analysis. Cary, NC. 440p.

Siddiqui M.A.R., Bhattacharjee J., Das Z.C., Islam M.M., Islam M.A., Haque M.A., Parrish J.J. \& Shamsuddin M. 2008. Crossbred bull selection for bigger scrotum and shorter age at puberty with potentials for better quality semen. Reprod. Domest. Anim. 43:74-79.

Smith B.A., Brinks J.S. \& Richardson G.V. 1989. Relationships of sire scrotal circumference to offspring reproduction and growth. J. Anim. Sci. 67:2881-2885.

Wildman E.E., Jones G.M., Wagner P.E., Boman R.L., Troutt H.F. \& Lesch T.N. 1982. A dairy-cow body condition scoring system and its relationship to selected production characteristics. J. Dairy Sci. 65:495-501. 